\begin{tabular}{|ll|}
\hline Received & $: 15$ Maret 2020 \\
Revised & $: 2$ April 2020 \\
Accepted & $: 20$ April 2020 \\
Online & $: 27$ April 2020 \\
Published & $: 30$ April 2020
\end{tabular}

\title{
Kajian Integral Lintasan Lévy dalam Mekanika Kuantum Fraksional untuk Membentuk Persamaan Schrödinger Fraksional
}

\author{
Chandra Halim ${ }^{1, \text { a) }}$, M. Farchani Rosyid ${ }^{1, b)}$, \\ ${ }^{1)}$ Departemen Fisika, Fakultas Matematika dan Ilmu Pengetahuan Alam, Universitas Gadjah Mada \\ 凹: a)chandra.halim.m@mail.ugm.ac.id, b)farchani@ugm.ac.id.
}

\begin{abstract}
The implementation of Lévy path integral generated by Lévy stochastic process on fractional Schrödinger equation has been investigated in the framework of fractional quantum mechanics. As the comparison, the implementation of Feynmann path integral generated by Wiener stochastic process on Schrödinger equation also has been investigated in the framework of standard quantum mechanics. There are two stochastic processes. There are Lévy stochastic and Wiener stochastic process. Both of them are able to produce fractal. In fractal's concept, there is a value known as fractal dimension. The implementation of fractal dimension is the diffusion equation obtained by using Fokker Planck equation. In this paper, Lévy and Wiener fractal dimension have been obtained. There are $\alpha$ for Lévy and 2 for Wiener/Brown fractal dimension. Fractional quantum mechanics is generalization of standard quantum mechanics. A fractional quantum mechanics state is represented by wave function from fractional Schrödinger equation. Fractional Schrödinger equation is obtained by using kernel of Lévy path integral generated by Lévy stochastic process. Otherwise, standard quantum mechanics state is represented by wave function from standard Schrödinger equation. Standard Schrödinger equation is obtained by using kernel of Feynmann path integral generated by Wiener/Brown stochastic process. Both Lévy and Feynmann Kernel have been investigated and the outputs are the Fourier Integral momentum phase of those kernels. We find that the forms of those kernels have similiraty. Therefore, we obtain Schrödinger equation from Lévy and Feynmann Kernel and also the comparison of Lévy energy in fractional quantum mechanics and particle energy in standard quantum mechanics.
\end{abstract}

Keywords: Lévy, Quantum Mechanics, Schrödinger. 


\begin{abstract}
ABSTRAK
Telah dilakukan kajian mengenai penerapan integral lintasan Lévy yang dibangkitkan dengan proses stokastik Lévy pada persamaan Schrödinger yang lebih umum dalam mekanika kuantum fraksional. Sebagai perbandingan, telah dikaji pula penerapan integral lintasan Feynmann dengan proses stokastik Wiener pada persamaan Schrödinger dalam mekanika kuantum standar. Terdapat dua proses stokastik yang digunakan yaitu proses stokastik Wiener dan proses stokastik Lévy. Kedua proses ini memiliki kesamaan yaitu proses yang menghasilkan fraktal. Dalam konsep fraktal, terdapat suatu nilai yang disebut sebagai dimensi fraktal. Penerapan konsep dimensi fraktal ini terletak pada persamaan difusi yang merupakan persamaan Fokker Planck pada proses stokastik Lévy dan Wiener. Pada kaji ulang ini, ditemukan dimensi fraktal Lévy sebesar $\alpha$ dan dimensi fraktal Wiener sebesar dua. Mekanika kuantum fraksional merupakan perumuman dari mekanika kuantum standar. Suatu keadaan dalam mekanika kuantum fraksional diwakili oleh bentuk fungsi gelombang pada persamaan Schrödinger fraksional yang dibangkitkan dari kernel integral lintasan Lévy. Sedangkan keadaan dalam mekanika kuantum standar diwakili oleh bentuk fungsi gelombang pada persamaan Schrödinger standar yang dibangkitkan dari kernel integral lintasan Feynmann Nilai kernel Lévy dan Feynmann ditinjau sedemikian rupa sehingga diperoleh bentuk yang paling sederhana dalam bentuk integral Fourier ruang momentum. Selanjutnya, dilakukan kaji ulang terhadap persamaan Schrödinger yang diteliti melalui nilai kernel integral lintasan masing-masing. Pada perhitungan akhir, diperoleh perbandingan antara nilai energi Lévy dengan energi pada mekanika kuantum standar.
\end{abstract}

Kata-kata kunci: Lévy, Quantum Mechanics, Schrödinger.

\title{
PENDAHULUAN
}

Mekanika kuantum merupakan ilmu dasar yang dapat menjelaskan berbagai sistem mikroskopik. Mekanika kuantum menjadi hal yang fundamental dalam penelusuran sistem mikroskopik dikarenakan mekanika kuantum mempelajari materi dan interaksinya dengan energi pada skala atom dan partikel subatomik. Dalam mekanika kuantum, perilaku dari partikel diwakili misalnya oleh suatu fungsi gelombang. Fungsi gelombang yang mewakili dinamika keadaan suatu partikel merupakan solusi dari persamaan Schrödinger gayut waktu (Suparmi 2011).

Persamaan Schrödinger adalah persamaan yang mengambarkan perkembangan (dinamika) keadaan suatu partikel dalam mekanika kuantum. Bentuk persamaan Schrödinger sejatinya adalah persamaan differensial berorde satu terhadap waktu yang solusinya merupakan vektor keadaan partikel. Vektor keadaan tersebut dapat disajikan dalam bentuk fungsi gelombang. Melalui fungsi gelombang tersebut, maka diperoleh penggambaran dinamika keadaan berupa besaran observabel seperti posisi dan momentum dari suatu partikel dalam dunia mekanika kuantum (Rosyid 2005). Persamaan Schrödinger merupakan persamaan mendasar dalam pengamatan dunia mikroskopik. Persamaan Schrödinger dapat mendeskripsikan perilaku materi dan interaksi partikel yang berukuran subatomik. Oleh sebab itu, formulasi persamaan Schrödinger menjadi hal yang penting dalam menguak dunia mikroskopis dalam fisika kuantum.

Istilah "fractal" pertama kali diperkenalkan oleh Mandelbrot ke dalam ilmu pengetahuan. Berdasarkan sejarah, contoh objek fisik fraksional adalah gerak Brown. Objek ini diteliti lebih lanjut dan dihubungkan dalam dunia kuantum. Dalam fisika kuantum, hasil pertama yang diperoleh dari penerapan konsep fraktalitas adalah integral lintasan Feynman pada pendekatan mekanika kuantum (Mandelbrot 1982). Feynman dan Hibbs (1965) merumuskan ulang mekanika kuantum non-relativistik sebagai integral lintasan yang berada pada lintasan gerak Brown. Oleh karena itu, latar belakang konsep fraksional yang dikembangkan oleh Feynman dan Hibbs mengarah ke mekanika kuantum standar (nonfractional).

Pada penelitian ini, akan dilakukan kaji ulang terhadap perluasan bagi konsep fraktalitas dalam fisika kuantum, yaitu kaji ulang konstruksi integral lintasan fraksional yang baru dan merumuskan ulang mekanika kuantum fraksional (Fractional Quantum Mechanics atau FQM) pada integral lintasan 
Lévy. Lebih tepatnya, FQM dalam bentuk integral lintasan merupakan ukuran fungsional yang dibangkitkan oleh proses stokastik Lévy. Proses stokastik Lévy merupakan perumuman bagi gerak Brown. Landasan bagi perumuman ini adalah teori distribusi probabilitas stabil yang dikembangkan oleh Lévy. Oleh karena itu, dari sudut pandang teori probabilitas ini disimpulkan bahwa hukum probabilitas stabil adalah bentuk umum bagi hukum probabilitas Gauss. Proses Lévy stabil $\alpha$ dikarakterisasi oleh index Lévy $\alpha, 0<\alpha \leq 2$. Untuk nilai $\alpha=2$, diperoleh proses Gauss atau proses gerak brown yang kemudian menghasilkan persamaan Schrödinger standar (Gardiner 1985). Secara umum, akan diformulasikan persamaan Schrödinger fraksional. Persamaan ini tentunya juga mencakup persamaan Schrödinger standar yakni pada persamaan diferensial dengan nilai $\alpha=2$. Oleh karena itu, bentuk perumuman yang akan dilakukan disebut dengan istilah "Mekanika Kuantum Fraksional"FQM.. Bentuk formulasi mekanika kuantum fraksional dapat menjelaskan fenomena teleportasi kuantum yang sebelumnya tidak dapat dijelaskan dengan mekanika kuantum standar. Hal ini didasari oleh perbedaan persamaan kontinuitas antara mekanika kuantum standar dan mekanika kuantum fraksional. Pada persamaan kontinuitas mekanika kuantum fraksional, suku kanan yakni rapat arus bernilai tidak nol. Sedangkan, persamaan kontinuitas mekanika kuantum standar, rapat arus bernilai nol. Kemunculan nilai rapat arus pada mekanika kuantum fraksional akan menjadi titik awal dalam penelusuran fenomena teleportasi kuantum (Wei 2016). Dengan demikian, kaji ulang ini diharapkan dapat membantu penelitian selanjutnya untuk mengungkapkan dunia teleportasi dalam dunia nyata.

\section{METODE PENELITIAN}

Metode penelitian yang digunakan adalah studi pustaka yakni dengan meninjau secara teoritis terkait mekanika kuantum fraksional yang didekati dengan penerapan integral lintasan Lévy dan mengaitkannya dengan mekanika kuantum standar yang selama ini telah diketahui (Laskin 2000). Adapun langkah-langkah penelitian yang dilakukan adalah.

1. Kajian tentang mekanika kuantum secara umum serta urgensinya dalam menghasilkan persamaan Schrödinger dengan menggunakan integral lintasan Feynman.

2. Mengkaji lebih dalam tentang proses stokastik Lévy yang menjadi pondasi dasar dalam memperoleh integral lintasan Lévy.

3. Mengkaji keterkaitan antara integral lintasan Lévy dan integral lintasan Feynman dalam keberlakuannya pada mekanika kuantum.

4. Merumuskan bentuk umum persamaan Schrödinger yaitu persamaan Schrödinger fraksional dalam mekanika kuantum fraksional.

5. Membuktikan bahwa mekanika kuantum fraksional merupakan bentuk umum dari mekanika kuantum standar dengan membandingkan persamaan Schrödinger standar dan persamaan Schrödinger fraksional.

\section{HASIL DAN PEMBAHASAN}

Penelitian ini bertujuan untuk mengkaji ulang terhadap perluasan bagi konsep fraktalitas dalam mekanika kuantum yaitu kaji ulang konstruksi integral lintasan fraksional yang baru dan merumuskan ulang mekanika kuantum fraksional (Fractional Quantum Mechanics atau FQM) pada integral lintasan Lévy. Dalam melakukan kaji ulang ini, ditelaah pula proses kontruksi integral lintasan Feynmann yang merupakan persamaan fundamental untuk memperoleh persamaan Schrödinger standar pada mekanika kuantum standar. Oleh karena itu, diperoleh bahwasanya mekanika kuantum fraksional merupakan perluasan konsep fraktalitas dari mekanika kuantum standar dengan persamaan Schrödinger standar di dalamnya.

Agar pemaparan hasil dan pembahasan lebih runtut dan jelas, hasil dibagi kedalam 2 subbab penjelasan yaitu mekanika kuantum standar sebagai kasus khusus dan mekanika kuantum fraksional sebagai perumuman dari mekanika kuantum standar. Pada subbab terakhir, ditunjukkan bentuk analog dari persamaan mekanika kuantum standar dengan mekanika kuantum fraksional jika disubsitusikan nilai $\alpha=2$ pada persamaan Schrödinger fraksional. Dengan demikian, dapat diperoleh kesimpulan bahwasanya mekanika kuantum fraksional merupakan perumuman dari mekanika kuantum standar. 


\section{Mekanika Kuantum Standar}

\section{Integral Lintasan Feynman}

Jika sebuah partikel dengan waktu awal $t_{a}$ pada posisi $x_{a}$ berangkat menuju titik pada posisi $x_{b}$ pada waktu $t_{b}$, maka partikel tersebut menempuh lintasan posisi sebagai fungsi waktu $x(t)$ dengan $x\left(t_{a}\right)=x_{a}$ dan $x\left(t_{b}\right)=x_{b}$. Dalam mekanika kuantum, untuk setiap kemungkinan lintasan berbeda yang ditempuh oleh partikel memberikan kontribusi suatu besaran yang disebut sebagai kernel mekanika kuantum $K_{F}\left\langle x_{b} t_{b} \mid x_{a} t_{a}\right\rangle$. Kernel merupakan besaran yang menggambarkan suatu nilai probabilitas dari seluruh lintasan partikel yang mungkin terjadi dari suatu titik awal ke titik akhir (Feynmann dan Hibbs 1965). Nilai kernel mekanika kuantum dapat digunakan untuk menemukan persamaan Schrödinger dalam wakilan fungsi gelombang. Jika terdapat partikel kuantum yang bergerak dalam potensial $V(x)$ sebagai fungsional dari lintasan partikel $x(\tau)$, maka nilai kernel $K_{F}\left\langle x_{b} t_{b} \mid x_{a} t_{a}\right\rangle$ secara matematis dapat dirumuskan sebagai berikut (Laskin 2006). Nilai kernel $K_{F}\left\langle x_{b} t_{b} \mid x_{a} t_{a}\right\rangle$ secara matematis dapat dirumuskan sebagai berikut.

$$
K_{F}\left\langle x_{b} t_{b} \mid x_{a} t_{a}\right\rangle=\int_{x\left(t_{a}\right)=x_{a}}^{x\left(t_{b}\right)=x_{b}} D x(\tau) \exp \left\{-\frac{i}{\eta} \int_{t_{a}}^{t_{b}} V(x(\tau)) d \tau\right\}
$$

dengan

$$
\int_{x\left(t_{a}\right)=x_{a}}^{x\left(t_{b}\right)=x_{b}} D x(\tau) \ldots=\lim _{N \rightarrow \infty} \int_{-\infty}^{\infty} d x_{1} \ldots d x_{N-1}\left(\frac{2 \pi i \eta \varepsilon}{m}\right)^{-1 / 2} \prod_{j=1}^{N} \exp \left\{\frac{i m}{2 \eta \varepsilon}\left(x_{j}-x_{j-1}\right)^{2}\right\}, \varepsilon=\frac{t_{b}-t_{a}}{N}
$$

dengan $m$ adalah massa partikel kuantum dan $\hbar$ adalah konstanta planck. Jika dinyatakan dalam integral Fourier maka Kernel integral lintasan Feynmann pada kasus partikel bebas dapat ditulis sebagai berikut.

$$
K_{F}\left\langle x_{b} t_{b} \mid x_{a} t_{a}\right\rangle=\frac{1}{2 \pi \eta} \int_{-\infty}^{\infty} \exp \left\{\frac{i p\left(x_{b}-x_{a}\right)}{\eta}-\frac{i p^{2}\left(t_{b}-t_{a}\right)}{2 m \eta}\right\} d p
$$

\section{Persamaan Schrödinger Standar}

Kernel $K_{F}\left\langle x_{b} t_{b} \mid x_{a} t_{a}\right\rangle$ yang telah didefinisikan pada persamaan mengambarkan perubahan dari sistem mekanika kuantum standar.

$$
\Psi_{f}\left(x_{b}, t_{b}\right)=\int_{-\infty}^{\infty} d x_{a} K_{F}\left\langle x_{b} t_{b} \mid x_{a} t_{a}\right\rangle \Psi_{i}\left(x_{a}, t_{a}\right)
$$

Untuk mendapatkan persamaan Schrödinger, dilakukan pendekatan infinitesimal pada t:

$$
\Psi_{f}\left(x_{b}, t+\varepsilon\right)=\int_{-\infty}^{\infty} d x_{a} K_{F}\left\langle x_{b}, t+\varepsilon \mid x_{a}, t\right\rangle \Psi_{i}\left(x_{a}, t\right)
$$

Pada pendekatan infinitesimal dan menggunakan definisi turunan fraksional kuantum Rietz pada nilai $\alpha=2$ serta transformasi Fourier diperoleh.

$$
i \eta \frac{\partial \Psi}{\partial t}=\left\{-\frac{(\eta \nabla)^{2}}{2 m}\right\} \Psi
$$




$$
i \eta \frac{\partial \Psi}{\partial t}=H \Psi
$$

dengan $H$ adalah operator hamiltonan.

$$
H=\left\{-\frac{(\eta \nabla)^{2}}{2 m}\right\}=\frac{p^{2}}{2 m}
$$

Persamaan (6) disebut sebagai persamaan Schrödinger standar pada partikel yang bergerak dalam satu dimensi (Laskin 2000).

\section{Mekanika Kuantum Fraksional}

\section{Integral Lintasan Lévy}

Nilai kernel levy $K_{L}\left\langle x_{b} t_{b} \mid x_{a} t_{a}\right\rangle$ secara matematis dapat dirumuskan sebagai berikut.

$$
K_{L}\left\langle x_{b} t_{b} \mid x_{a} t_{a}\right\rangle=\int_{x_{a}}^{x_{b}} D x(\tau) \exp \left\{-\frac{i}{\eta} \int_{t_{a}}^{t_{b}} V(x(\tau)) d \tau\right\}
$$

dengan $V(x(\tau))$ adalah potensial sebagai fungsional dari partikel lintasan Lévy $x(\tau)$, dan ukuran integral lintasan fraksional didefinisikan sebagai.

$$
\int_{x_{a}}^{x_{b}} D x(\tau) \ldots=\lim _{N \rightarrow \infty} \int_{-\infty}^{\infty} d x_{1} \ldots d x_{N-1}(\eta)^{-N}\left(\frac{i D_{\alpha} \varepsilon}{\eta}\right)^{-\frac{N}{\alpha}} \prod_{j=1}^{N} L_{\alpha}\left\{\frac{1}{\eta}\left(\frac{\eta}{i D_{\alpha} \varepsilon}\right)^{\frac{1}{\alpha}}\left|x_{j}-x_{j-1}\right|\right\} \ldots
$$

dengan $D_{\alpha}$ adalah koefisien difusi kuantum fraksional dengan satuan $\mathrm{erg}^{1-\alpha} \mathrm{cm}^{\alpha} \mathrm{sec}^{-\alpha} . \eta$ adalah konstanta planck, $x_{0}=x_{a}, x_{n}=x_{b}$, dan $\varepsilon=\frac{t_{b}-t_{a}}{N}$. Distribusi Lévy $L_{\alpha}$ dapat dituliskan sebagai fungsi $\mathrm{H}$ fox yaitu.

$$
(\eta)^{-1}\left(\frac{i D_{\alpha} t}{\eta}\right)^{-\frac{1}{\alpha}} L_{\alpha}\left\{\frac{1}{\eta}\left(\frac{\eta}{i D_{\alpha} t}\right)^{\frac{1}{\alpha}}|x|\right\}=\frac{1}{\alpha|x|} H_{2,2}^{1,1}\left\{\frac{1}{\eta}\left(\frac{\eta}{i D_{\alpha} t}\right)^{\frac{1}{\alpha}}|x|_{(1,1),\left(1, \frac{1}{2}\right)}^{\left(1, \frac{1}{\alpha}\right),\left(1, \frac{1}{2}\right)}\right\}
$$

dengan $\alpha$ adalah indeks Lévy pada interval $1<\alpha \leq 2$ (Laskin 2000).

Pada kasus partikel bebas $V(x)=0$, maka nilai kernel integral lintasan Lévy hanya bergantung pada bagian ukuran integral lintasan saja. Untuk nilai $N=1$, maka nilai kernel integral lintasan Lévy dapat dinyatakan dalam bentuk fungsi H-Fox $H_{p, q}^{m \cdot n}\left\langle z \mid \begin{array}{l}\left(a_{1}, A_{1}\right),\left(a_{2}, A_{2}\right) \\ \left(b_{1}, B_{1}\right),\left(b_{2}, B_{2}\right)\end{array}\right\rangle$ yang lebih lanjut dapat dilihat pada (Fox 1961) yaitu.

$$
(\eta)^{-1}\left(\frac{i D_{\alpha}\left(t_{b}-t_{a}\right)}{\eta}\right)^{-\frac{1}{\alpha}} L_{\alpha}\left\{\frac{1}{\eta}\left(\frac{\eta}{i D_{\alpha}\left(t_{b}-t_{a}\right)}\right)^{\frac{1}{\alpha}}\left|x_{b}-x_{a}\right|\right\}=\frac{1}{\alpha\left|x_{b}-x_{a}\right|} H_{2,2}^{1,1}\left\{\frac{1}{\eta}\left(\frac{\eta}{i D_{\alpha}\left(t_{b}-t_{a}\right)}\right)^{\frac{1}{\alpha}} \mid x x_{(1,1),\left(1, \frac{1}{2}\right)}^{\left(1, \frac{1}{2}\right),\left(1, \frac{1}{2}\right)}\right\}
$$


Dalam bentuk integral fourier, kernel Lévy pada kasus partikel bebas dapat dituliskan sebagai berikut

$$
K_{L}\left\langle x_{b} t_{b} \mid x_{a} t_{a}\right\rangle=\frac{1}{2 \pi \eta} \int_{-\infty}^{\infty} \exp \left\{\frac{i p\left(x_{b}-x_{a}\right)}{\eta}-\frac{i D_{\alpha}|p|^{\alpha}\left(t_{b}-t_{a}\right)}{\eta}\right\} d p
$$

\section{Persamaan Schrödinger Fraksional}

Kernel $K_{L}\left\langle x_{b} t_{b} \mid x_{a} t_{a}\right\rangle$ yang telah didefinisikan pada persamaan diatas mengambarkan perubahan dari sistem mekanika kuantum fraksional.

$$
\Psi_{f}\left(x_{b}, t_{b}\right)=\int_{-\infty}^{\infty} d x_{a} K_{L}\left\langle x_{b} t_{b} \mid x_{a} t_{a}\right\rangle \Psi_{i}\left(x_{a}, t_{a}\right)
$$

Untuk mendapatkan persamaan Schrödinger fraksional dilakukan pendekatan infinitesimal pada $t$

$$
\Psi_{f}\left(x_{b}, t+\varepsilon\right)=\int_{-\infty}^{\infty} d x_{a} K_{L}\left\langle x_{b}, t+\varepsilon \mid x_{a}, t\right\rangle \Psi_{i}\left(x_{a}, t\right)
$$

Pada pendekatan infinitesimal, menggunakan turunan fraksional kuantum Rietz serta transformasi Fourier maka diperoleh.

$$
\begin{gathered}
\Psi(x, t)+\varepsilon \frac{\partial \Psi(x, t)}{\partial t}=\Psi(x, t)+i \frac{D_{\alpha} \varepsilon}{\eta}(\eta \nabla)^{\alpha} \Psi(x, t) \\
i \eta \frac{\partial \Psi}{\partial t}=\left\{-D_{\alpha}(\eta \nabla)^{\alpha}\right\} \Psi \\
i \eta \frac{\partial \Psi}{\partial t}=H_{\alpha} \Psi
\end{gathered}
$$

dengan $H_{\alpha}$ adalah operator hamiltoninan fraksional.

$$
H_{\alpha}=E_{\alpha}=-D_{\alpha}(\eta \nabla)^{\alpha}=D_{\alpha}|p|^{\alpha},|p|^{\alpha}=-(\eta \nabla)^{\alpha}
$$

Persamaan (16) disebut sebagai persamaan Schrödinger fraksional pada partikel bebas yang bergerak dalam satu dimensi (Laskin 2000).

\section{KESIMPULAN}

Berdasarkan hasil yang telah dikaji dapat disimpulkan bahwa persamaan Schrödinger memiliki bentuk yang sama dengan persamaan Schrödinger standar dalam kasus partikel bebas. Hanya saja, dalam persamaan Schrödinger fraksional terdapat tambahan variabel $D_{\alpha}$ yakni koefisien difusi kuantum fraksional dengan satuan $\mathrm{erg}^{1-\alpha} \mathrm{cm}^{\alpha} \mathrm{sec}^{-\alpha}$. Tetapi pada persamaan Schrödinger standar tidak ditemukan tambahan variabel. Melalui kaji ulang persamaan, diperoleh nilai $D_{\alpha}$ pada pada nilai indeks Lévy $\alpha=2$ adalah $\frac{1}{2 m}$. Jika nilai $D_{2}$ dimasukkan kedalam persamaan Schrödinger fraksional maka diperoleh persamaan Schrödinger standar dalam kasus partikel bebas. Perbandingan antara mekanika kuantum standar dan mekanika kuantum fraksional terlihat pada persamaan Schrödinger yang diperoleh dari kedua jenis integral lintasan yang berbeda. Persamaan Schrödinger fraksional menggunakan integral lintasan Lévy sebagai pendekatannya sedangkan persamaan Schrödinger standar menggunakan integral lintasan Feynmann. Walaupun demikian, terlihat bahwa mekanika kuantum fraksional merupakan perumuman dari mekanika kuantum standar yakni pada nilai indeks Lévy $\alpha=2$. 


\section{UCAPAN TERIMAKASIH}

Ucapan terima kasih penulis kepada bapak Dr.rer.nat. M. Farchani Rosyid, M.Si sebagai pembimbing dalam menulis paper ini kepada bapak Romy Hanang Setya Budhi, Ph,D dan Mirza Satriawan Ph.D. yang telah memberikan saran yang konstruktif dalam penulis untuk menyempurnakan karya tulis ini.

\section{REFERENSI}

Feynman, R. P. \& Hibbs A. R. (1965). Quantum Mechanics and Path Integrals. New York : McGrawHill.

Fox, C. (1961). The G and H Functions as Symmetrical Fourier Kernels. Transactions of the American Mathematical Society, 98(3): 395-429.

Gardiner, C.W.(1985). Handbook of Stochastic Methods, Berlin : Springer.

Laskin, N. (2000). Fractional Quantum Mechanics and Lévy Path Integrals. Physics Letter A 268, 298305.

Laskin, N.(2006).Lévy Flight over Quantum Paths. New York : Sciencedirect.

Mandelbrot, B.B.(1982).The Fractal Geometry of Nature. New York : Freeman.

Rosyid, M.F.(2005). Mekanika Kuantum Model Matematis Bagi Fenomena Alam Mikroskopis Tinjauan Nonrelativistik. Skripsi, Fisika FMIPA UGM.

Suparmi. (2011). Mekanika Kuantum II. Surakarta : Fisika FMIPA Universitas Sebelas Maret.

Wei, Y. (2016). The Quantum Mechanics Based on a General Kinetic Energy, Int. J. Sci. Res. 4: 121. 